\title{
Important about the Manipulations of the Pharmaceutical Concerns, the OSMS (One Step Melanoma Surgery) and the Drug Induced Melanoma: “You Dream Things; You Say, 'Why?' But I See Things Before My Eyes; And I Say 'Why Not?'”
}

Tchernev $\mathrm{G}^{1,2^{*}}$ and Temelkova $\mathrm{I}^{1,2}$

${ }^{1}$ Medical Institute of Ministry of Interior (MVR), Department of Dermatology, Venereology and Dermatologic surgery, General Skobelev 79, 1606 Sofia

${ }^{2}$ Onkoderma- Clinic for Dermatology, Venereology and Dermatologic Surgery, General Skobelev 26, 1606 Sofia

Received: January 30, 2019; Accepted: January 31, 2019 ; Published: February 04, 2019

*Corresponding author: Dr. Georgi Tchernev, Medical Institute of Ministry of Interior (MVR), Department of Dermatology, Venereology and Dermatologic surgery, General Skobelev 79, 1606 Sofia, Bulgaria, Tel: 00359885588424;E-Mail: georgi_tchernev@yahoo.de

\section{Abstract}

Approach variability in melanoma surgery is more likely to be artificially created and refers mainly to: 1) the surgical safety margins; 2) the clinician's compliance with the patient's choice to pre-define these margins for a better cosmetic outcome; 3 ) the interval within which re-excisions may be carried out; 4)discrepancy between the clinically respected and histologically established tumor resection margins; 5)as well as the lack of additional guidelines for re-excisions within the already established differences between the clinically and histologically established resection margin. These "inaccuracies" make it difficult to implement the current guidelines and often lead to confusion. We assume that the approach variability is for sure not established and based only on the opinion of the so-called 'expert groups'!

Reaching advanced stages in melanoma patients is related to making decision on the choice between chemotherapy and modern targeted therapy or immunotherapy. Unfortunately, the results are rather unsatisfactory at the moment. For this reason, we rely on the cheapest and most efficient method, i.e. changing the baseline criteria for surgical melanoma treatment or changing the initial approach.

Clarification of the baseline positions! Something that would cost a lot, but would contribute much, and certainly more (and would be cheaper as an initial establishment)to the better prognosis for all melanoma patients. This change would modify a number of 'meaningful' medico-socio-politico-economic relationships. And right now, that is why it is undesirable! By laying the foundations for one step melanoma surgery, we believe we set the beginning of a better prognosis and survival for patients with cutaneous melanoma.

Key words: Novartis; pharmaceutical industry; one step melanoma surgery; valsartan; melanoma

\section{Introduction}

Treatment of melanoma patients should be simplified [1]. Melanoma surgery undergoes and should undergo evolution. Whether this evolution would be assumed by dermatologists and dermato-oncologists is questionable. Especially when the following problematic points are present:

1) During their training, the so called "beginner dermatologists" are usually under-trained to operate (national experience/ international experience). Gaining individual experience through risky actions (to save time and maximize profits)leads to serious consequences in a high percentage of cases. These events are not uncommon.

2) In case of underestimated and not well-discussed initial criteria for surgical treatment of melanoma (variability of choice/ AJCC), an increasing rate of patients reach advanced, end or terminal stages where even good surgical skills cannot help.

These are apparently the most important points determining the negation, confusion and hesitation of our colleagues about the surgical treatment of cutaneous melanomas, on the one hand. We present a new algorithm for the treatment of melanomas (at all stages/OSMS criteria from the Bulgarian Society for Dermatologic Surgery) within one surgical session. We discuss the reasons leading to the denial and lack of wide implementation of the methodology.

The most important question or dilemma remains, who neglects and permits the lack of optimization (or poor audibility and acceptability) of the effective new methods of melanoma 


\section{“You Dream Things; You Say, 'Why?' But I See Things Before My Eyes; And I Say 'Why Not?”}

treatment shared not only by us? The answer should be prosaic. Certainly or probably (without any accusation), these are also those who are interested in using more expensive drugs at more advanced stages! The latter should also benefit from the lower education of the medical staff with a view to making it easier to manipulate them.

The genius of the approaches in medicine, and in general, is or should be sought in the simplicity of our decisions. The various guidelines for surgical treatment of cutaneous melanomas over the decades do not speak in favour of simplifying the algorithms but rather for aggravating them by lowering the initial criteria and focusing on the response at later stages, namely "when the spirit has already left the bottle" (patients in advanced stages) [2]. Without going deeper into this otherwise sensitive topic, we should ask at least one of the following questions: Is it possible to have one step melanoma surgery with or without preoperative application to determine tumor thickness? The answer is YES $[3,4]$ ! Do these patients/patient groups benefit from the abovementioned methodology? The answer is YES again $[3,4]$ ! Is it thus possible to create prerequisites for at least a significant number of patients, related to a more favourable long-term prognosis/survival, etc.? The answer is definitely YES [3-6]! Considering that the total melanoma incidence around the globe is approximately 150000 (for 2018, male/female) per year (registered cases!!!)[7], it should be asked whether saving 150000 re-excisions would lead to treatment optimization and would save money for the different healthcare systems around the world? The answer is once again explicit: approximately between 500 million- and 1 milliard less a year! This is the money saved just by not doing additional surgical interventions (secondary excisions/ secondary excisions with SLN biopsy)!

Indirectly, we should think about whether the current guidelines, and why these guidelines create prerequisites for a kind of freedom of action, a kind of variability of approach [2]!? Without this being definitely justified! More importantly, who is interested in this? A higher number of patients with cutaneous melanomas, to reach probably advanced stages? To whom innovative "ungodly expensive" drugs are administered? To which resistance surely develops within 2-4 years?

Another important issue would be directly addressed to the authors of melanoma surgery guidelines in the USA: Why, since these facts are already publicly available and the results are known (published by the Bulgarian and French dermatosurgical schools), you are still moving along the "well-traveled paths of comfort", which helps you kind of drain the health system and health insurance funds, meanwhile threatening patients' health to a certain extent (most likely)[1,4-6,8]! Or at least a large number of patients [8]! The answer is simple and is also contained in a single word: capitals! Rather, the movement of capitals! Capitals that brought certain systems and entire governments to financial crash, instability, wars and manipulations! At all levels and in any sphere. Or simply put, the American way! Allow me smile! Neoliberal or capitalist way of thinking, remodeled by a pattern desired by us!? Tightened by the hoop of denial and unreceptiveness due to the desire for maximum profit, no matter at what price. Even if it is a human life!
Another important and final question to the readers would be, "Do you want to change this way of thinking and action?" If the answer is YES, it may be worth taking 4 to 5 minutes on reading this paper!

One step melanoma surgery undoubtedly turned out to be one of the innovations of our time $[1,3,4,8]$. It is applicable to groups of patients where the tumour thickness could be measured preoperatively/by ultrasound (while in parallel also determining the status of the locoregional lymph nodes)but also to patients where the ultrasound assessment is not absolutely obligatory $[1,3,4,8]$.

\section{Methods/problems, AJCC- current state}

The existing standards for the melanoma treatment require the conduct of the so-called excision biopsy followed by a histopathological assessment of the tumour thickness and, depending on it: performing re-excisions with different fields of additional surgical security, combined or not with the determination of a draining lymph node [2]. The drawbacks of this methodology are many [2]: 1) the different treatment time of the preparations, which, according to the institution, may not coincide with the two-week period for performing a re-excision, for example, 2) the willingness for a second opinion of the patients themselves, which makes the re-excision pointless if the deadlines for the latter are not met [2]. As well as 3) the refusal of re-excision for various other reasons, which can be both objective and subjective [2].

\section{Results/problems solving/novel approach/open questions}

The spiral of randomness or spiral of manipulations? Or maybe a little of both! The search for interconnections in medicine and medical literature is not forbidden (at least officially at this stage, especially if your direction of thinking coincides with ours!). Unlike the slightly emotional nature of the comments and expression of positions. Which is also a kind of censorship ... according to someone!? Which is necessary. To whom? ... It is rather clear! Rarely there are journals allowing for free opinion to be expressed on a given subject that is strictly scientific or practically specific. The reasons for this censorship are often, 1) the concealment of important information related to the medical/economic nature of the relationship between two parties (medical staff and pharmaceutical industry's interests), and 2) the commercial and political nature of a wider activity, which by presumption should be disinterested, ... or presented to society as such (politics, political circles and pharmaceutical companies) $[9,10]$. Due to the fact that these activities in general are indirectly related to melanoma surgery, we should not ... hum ... pay particular attention to them! Let us share a different experience and different point of view. And time will tell if we were right or not! The problem is there or lies in the fact that patients are affected, as in the case of Valsartan and melanoma! Irbesartan and melanoma! But this will be discussed in a while!

We will go back for a moment to the medical aspects and arguments that are part of the stagecoach! 


\section{“You Dream Things; You Say, 'Why?' But I See Things Before My Eyes; And I Say 'Why Not?”'}

Because of these facts, the preoperative assessment of tumour thickness creates several unique opportunities to minimize these problems and to optimize the approach to the patients to a maximal extend, namely $[6,8]$ :

1) For all lesions that are clinically and dermatoscopically indicative for cutaneous melanomas, preoperative ultrasound of the primarius should be performed. If the primarius has a tumour thickness of less than or up to $1 \mathrm{~mm}$, then a re-excision with a surgical security field of $1 \mathrm{~cm}$ in all directions should be planned without removing the draining lymph node.

2) If the primarius has a tumour thickness above $1 \mathrm{~mm}$ and less than $2 \mathrm{~mm}$, the surgical security field will be $1 \mathrm{~cm}$ and will be combined with the simultaneous removal of the draining lymph node within one surgical session [6].

3) In tumours with a thickness between 2 and $4 \mathrm{~mm}$, echography could be used analogously to those already mentioned in items 1 and 2, with the surgical security field being $2 \mathrm{~cm}$ in all directions.

4) For tumors with a thickness greater than $4 \mathrm{~mm}$, the singlestep melanoma surgery also finds an adequate application. If the locoregional lymph nodes are affected, the primarius is removed within one surgical session along with them (and a corresponding field of surgical security). If they are not affected (of clinical and ultrasound point of view), the determination of a draining lymph node is not recommended (even in tumors over $4 \mathrm{~mm}$ ) due to the fact that the metastasis is probably already performed: 1) haematogenously, 2) by accessory lymphatic vessels, or 3 ) for one reason or another, the draining lymph node has not captured the tumor cells.

In all the three options described, the optimization is due to 1) reducing the number of surgical interventions from two to one, 2) the better control of the disease as a whole: the absence of risk of delaying a potential re-excision or patient's failure to attend for the second surgical intervention, and 3) limiting the costs of the subsequent potential second hospitalization $[1,2]$. The crucial step of the procedure remains ultrasound. $20 \mathrm{MHz}$ ultrasound may overestimate tumor thickness due to the lymphocytic peritumoral infiltrate. Therefore, $75 \mathrm{MHz}$ has been suggested to overcome this possible drawback [11].

5)Recently published data evidencing that the single-step melanoma surgery is also applicable to patients with clear clinical and dermatoscopic criteria for thin cutaneous melanomas, even without the need for preoperative tumour thickness measurement $[3,4]$, are also of interest. Re-thinking the approach to patients with cutaneous melanomas is yet to come.

CAVE: Valsartan/Irbesartan induced melanoma? From manipulations to genocide!? The "hidden role" of pharmaceutical industry?!

Let's go back to causality, which is difficult to be influenced or formalized in view of our positions. That is why there is a certain touch of emotion in our position and statement. We will use a few examples to try and explain in a different way, why progress is sometimes suppressed or ignored!?
Let us also devote a few lines to angiotensin receptor antagonists, their carcinogenic risk, melanoma, dermatological surgery, and capital distribution at different levels. Links that seem at first glance at least absurd. However, after an in-depth analysis, they appear very logical, probable and possible. Another interesting point is censorship and why it is necessary? Censorship is usually imposed when something "ominous" might be revealed and/or someone loses considerable capital. In this case, the parties losing capital are the pharmaceutical companies and their "political veils" that have a huge influence on our medical activity and are trying to guide us in certain directions to "someone's benefit" [10,12-15]!

Valsartan for example! Or losartan? Or Irbesartan? Or any sartan? Medication with carcinogenic effect due not only to NDMA content? $[16,17]$. To Valsartan itself, shall we ask $[16,17]$ !? Or to some of its "accidental" carcinogenic supplements? And how do they get there? From the sky? From the "Chinese groundwaters? " Or through the "acid rains" of Sri Lanka and New Guinea! No, dear colleagues and friends, it is most likely that this is done through the "Bulgarian lemonade" and its export abroad [Figures 1a-1d]! We should ask, how more than one carcinogenic ingredients have been added/fallen into a drug $[16,17]$ ? In addition to the fact that the number of companies involved in the scandal grows [18-20]? Which means that one or more ingredients "have been added" simultaneously during the production cycle of dozens of companies? Originally Chinese, and later on others. Also companies in Germany, probably [16]!? We have data provided to EMA and the FDA that also some German companies are suspected to produce "carcinogenic" valsartan for, let's say a leading pharmaceutical company [16], [Figure 2a]? And these data are more than startling? Recently, it has been found that the list of drugs containing generics, which are at the same time added to the lists of prohibited agents, is growing tremendously [18-20]. It has recently been found that in addition to NDMA, another carcinogen, i.e. NDEA, is also contained in valsartan [17]! Which is also found in irbesartan [21]!

We hereby inform our readers that there are melanoma patients who have developed the disease some years following the administration of angiotensin receptor antagonists (or during their administration), produced within the EU, which are still not included in the FDA's lists of prohibited melanoma agents $[16,22,23]$, [Figure 2]! Most of these data are registered with the FDA, EMA and/or the Bulgarian Drug Agency. The absolute information curtain drawn in Bulgaria, but also in America and Germany (The Guardian, Wall Street Journal, Washington Post, New York Times ......, Bloomberg, investor.bg, clinica.bg, etc.), Preventing us from sharing data in the official press (as well as expressing our opinion, albeit hypothetically/probably, logically), made us do it in a non-traditional way, i.e. in a medical journal. Interestingly, one company, which is among the top ten pharmaceutical giants, produces, in addition to valsartan, medications for the treatment of advanced melanoma [16]!? Though slightly conspiratorially and hypothetically, however not accusatory, but not totally out of question, this creates problems (carcinogenic valsartan, produced by one company 


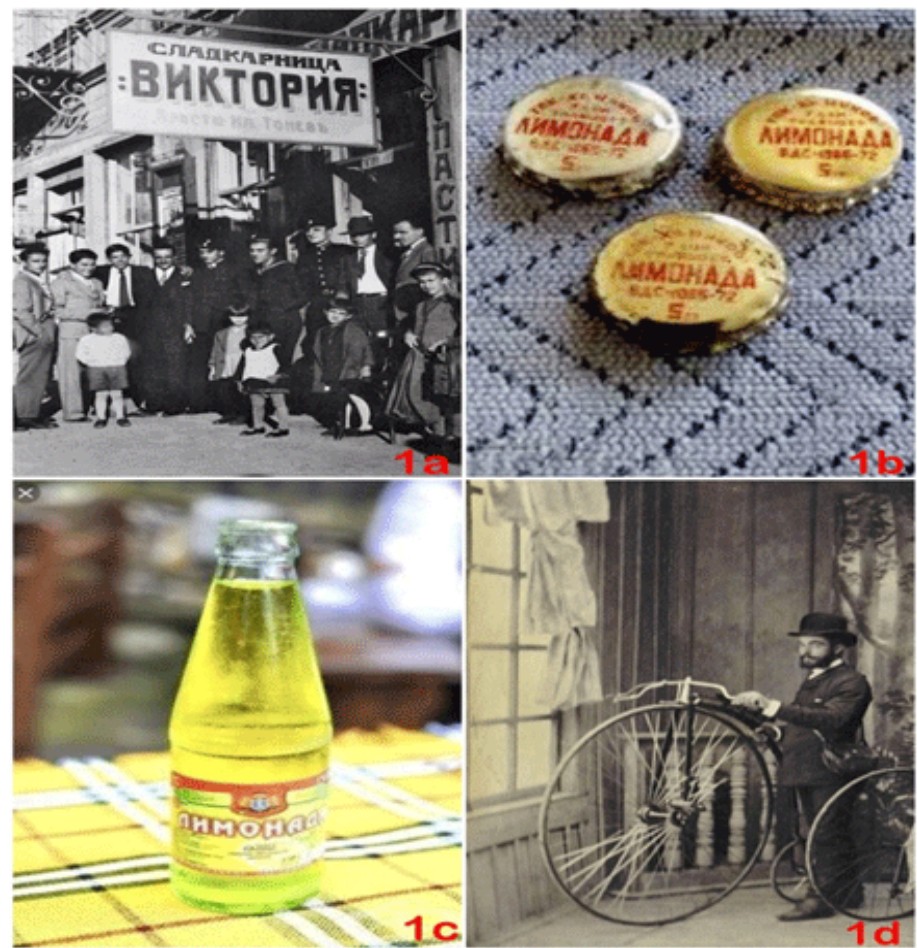

Figure 1a: APastry shop "Victoria" is the first one in Bulgaria where ice cream was sold from a foreign machine.

The owner of the elite establishment was Krastyo Tonev, who remained in history as one of the most famous confectioner not only in Tarnovo and the region, but also in the whole country. He was rewarded as master confectioner with an honorary diploma and a golden medal, I degree from the first Bulgarian food craft exhibition held in Sofia in 1938. Another famous citizen of Tarnovo was Methodi Hadjipetkov.

He decided that he can produce soft drinks. And not just in any way, but in closed bottles with glass balls and siphon. For this purpose he built a factory, hired workers and in one summer day simultaneously at the Tarnovo's market and in all pubs (around 100 at that point of time) cold lemonade appeared.

The citizens devour the unknown drink, first with suspicion and later on with pleasure. Methodi Hadjipetkov had already seen the American lux and decided to carry it over to Bulgaria, to the extent possible. In his shop appeared German cigars, belugas, processed in the French firm "Amio Frer", Russian caviar. Next to his matured wine was offered "Malaga" from Spain; for appetizer no more, no less Dutch and Swiss cheeses as well as cognac and rum from Bordeaux were imported (from the article of Grigor Nikolov, 1 April 2018, online information website Obekti).

Figure 1b, 1c: Bulgarian lemonade at close. No data for carcinogenic materials in it till the present moment!

Figure 1d: Modern vehicles from one time. They called them bikes.

or currently dozens of companies? And the number of the companies in the prohibition list grows every day?), for which we already have a solution (targeted therapy for the different types of cancers provided by the same company ... let's say?)! Finally yet importantly, we would like to share that a careful reading of the medical history, followed by a thorough clinical examination and good awareness ... this is exactly what creates the prerequisites for a good analysis of the overall picture! We do not blame the company, which has been silent for a few months on the subject "like a fish on dry land" and provides no official explanation of what is happening [16]! But we have the data already published [16]! In terms of the millions of patients who take valsartan around the world, this sounds somewhat weird! Such "great companies" are accustomed to paying fines of 390 million for criminal acts under the US law, as well as 50 million for bribery of medical personnel due to unregulated relationships in neighboring Greece $[15,24,25]$ ! So it would not be right to expect a response from such a "pharmaceutical giant", wouldn't it [15,24-25]?! The answers would be compromising, and the bank transfers in the form of fines may be lived with ...), most simply put! There are no shadows of doubt! The problem has not been personalized! As if this has never happened! 

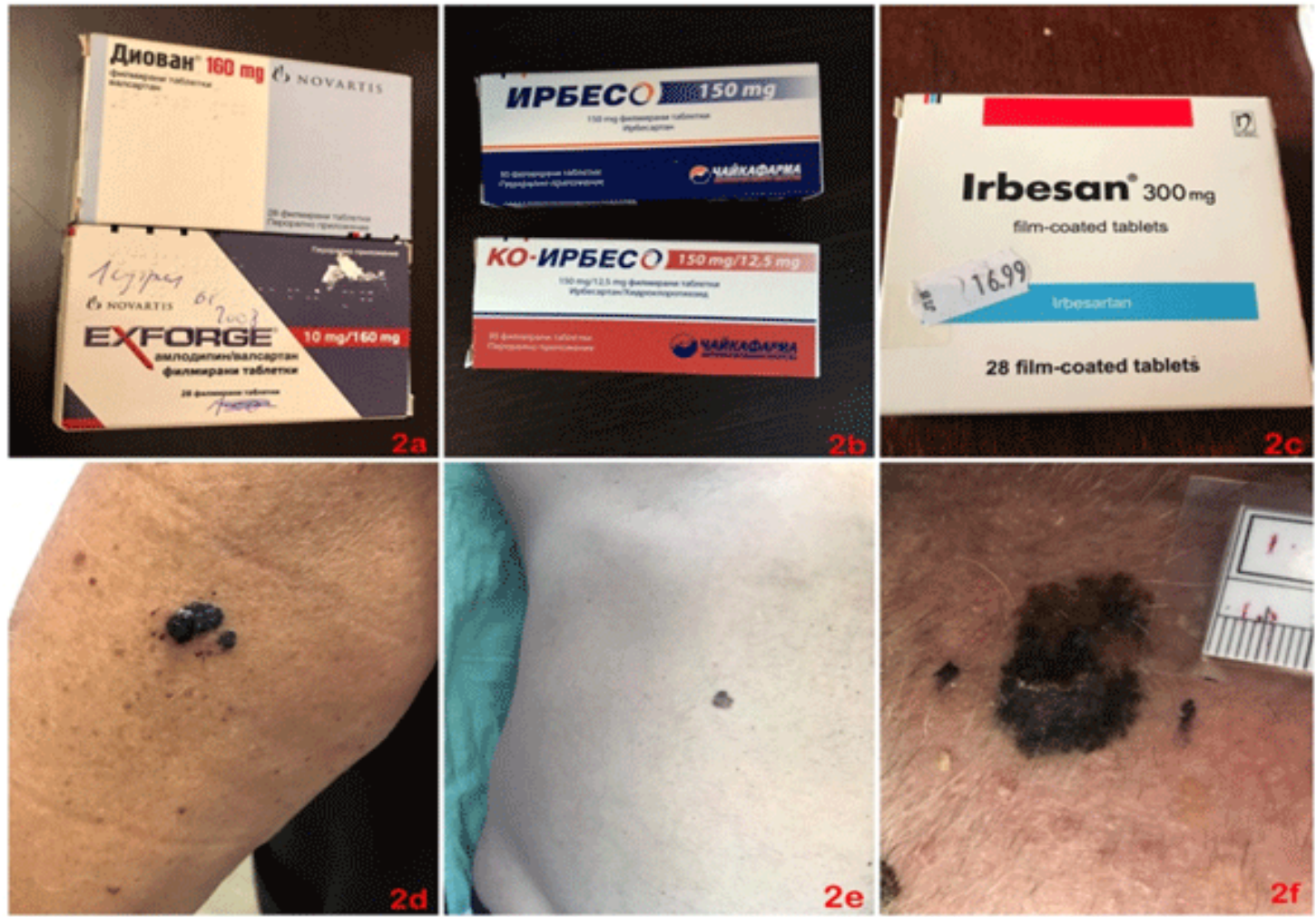

Figure 2a/2d: PA patient who developed a pigment lesion after taking Valsartan (16) as the valsartan dose increases, the latter evolved to cutaneous melanoma with single metastasis in a lymph node (16). Operated in two stages according to the AJCC guidelines (16).

Figure 2b/2e: Young patient with available pigment lesion prior to Irbesartan's intake, which subsequently rapidly changes its color, shape and size, and grows into cutaneous melanoma (22). Successfully operated through one-step melanoma surgery (OSMS).

Figure 2c/2f: Patient with available (originally) lesion with a nail size which, after the start of treatment with valsartan for a short time, changes its shape, color and size, and turn into cutaneous melanoma. Successfully operated through one-step melanoma surgery (OSMS) (23).

\section{"The Connection! "}

The developers of the carcinogenic valsartan and irbesartan hardly differ from those who impede the real surgical activity in medicine and thus have the opportunity to sell or realize their products to patients with advanced stages of melanoma, for example! And, if hypothetically, we look at the facts: 1) the ubiquitous sale and distribution of carcinogenic products (for example, Valsartan, irbesartan, etc.) that, in the corresponding genetic predisposition, generate a variety of tumors; and 2) in parallel, the same companies are looking for solutions to treat tumors at an advanced stage? And de facto, we have such an examples! These are the non-medical, some kind of paramedical, maybe paracriminal (again hypothetically) or absolutely criminal units? These units are also the cause of devaluation and oblivion of good medical practices, and in this particular case, they directly or indirectly impede the one step melanoma surgery!? Because it is the one step melanoma surgery that prevents and disrupts the "Pseudogiant" or "pseudo-manipulation" hegemony! That is, OSMS is our response in order to interrupt the transition from point 1 to point 2 (as mentioned in the previous sentence)! This is also our way to try and alert the patients and our colleagues about the risks of point 1 , which are not fully clarified both in the medical literature and media! There are companies on the market selling drugs, for which there are very serious assumptions (official experimental data- last reference at the end of the sentence), ... that potentiate the possible development and advancement of cutaneous melanomas [16,22,23,26]!

\section{Conclusions}

According to a number of colleagues, it is impossible to accurately measure tumor thickness of thin melanomas. There remains an open question, i.e. why one step melanoma surgery is not used in patients with thin melanomas (clear clinical and dermatoscopic findings)? With a surgical margin of $1 \mathrm{~cm}$ in all directions? The Bulgarian Society for Dermatologic surgery (official site: BULSDS.com)is the first in the world that has officialized and implemented (in practice)this unique opportunity $[3,4]$. And with perfect clinical results $[3,4]$ ! In approximately at least $60-90 \%$ of patients with thin melanomas below $1 \mathrm{~mm}$ or 


\section{“You Dream Things; You Say, 'Why?' But I See Things Before My Eyes; And I Say 'Why Not?”}

melanoma in situ, preoperative ultrasound measurement of tumor thickness could be avoided and replaced by clinical and dermatoscopic assessment $[3,4]$ !

The objective of one step melanoma surgery is to 1)achieve a lower rate of patients reaching end or terminal stages, 2)improve the survival in these patients, 3)limit the number of surgeries, 4)optimize the clinical pathway financing $[3,4]$. And we believe that this has already been achieved in a significant number of patients [1,3-6]! The idea was implemented for the first time in the Department of Dermatology and Venereology at the Medical Institute of the Ministry of Interior, Sofia, Bulgaria!

Everything is determined by the simplicity of relations and the simple analysis of data that are concealed in silence or veiled (based on the following arguments: according to the expert opinion, the expert groups involved in thid problem ... :-)... .. in the American melanoma treatment journals ...... For example [2]!

From the ancient times, Medicine and Philosophy draw their strength from the Balkans and the Middle East!

The comments and debates on the hotspots - that is what ensures progress! And, although rarely, this progress has begun from the Balkan and Middle East regions, and not from the "newly emerged overseas manipulative claims"! Statements stemming from sinking economies, scraping by all possible means to survive! Even at the cost of human lives!

\section{Important}

The information presented on this paper is not in its essence a confirmation of the causal link between the medicinal products and the observed effects. The information relates to suspected and supposed links based on medical observation and opinions, as well as concerns about them. The above findings are based on the statutory obligation of the persons concerned to inform the competent authorities of suspected serious adverse drug reactions in accordance with national and European legislation related to tracking of the drug safety.

We pay attention to the readers of this paper that they should not stop taking the above mentioned medicines at their discretion without consulting a competent medical practitioner.

\section{References}

1. Tchernev G, Chernin S, Lozev I, Lotti T, Stavrov K, Temelkova I et al. Innovative One Step Melanoma Surgical Approach (OSMS): Not a MythIt's a Reality! Case Related Analysis of a Patient with a Perfect Clinical Outcome Reported from the Bulgarian Society for Dermatologic Surgery (BULSDS)! Open Access Maced J Med Sci. 2018;6(4):673-674. doi: 10.3889/oamjms.2018.194

2. Bichakjian K, Halpern C, Johnson M, Foote Hood A, Grichnik J, Swetter M. Guidelines of care for the \&management of primary cutaneous melanoma. J Am Acad Dermatol. 2011;65(5):1032-1047. doi: 10.1016/j.jaad.2011.04.031
3. Tchernev G, Temelkova I. The Novel Surgical Margin for One Step Melanoma Surgery (OSMS) (Without Using Ultrasonography Preoperatively): The End of Conformity! "Vivere militare est!" Open Access Maced J Med Sci. 2018;6(7):1263 -1266. doi: 10.3889/ oamjms.2018.288

4. Tchernev G, Temelkova I, Stavrov K. One Step Melanoma Surgery (OSMS) Without Using Ultrasonography for Preoperative Tumour Thickness Measurement? - „A Question that Sometimes Drives Me Hazy: Am I or Are the Others Crazy!" Open Access Maced J Med Sci. 2018;6(6):1085-1090. doi: 10.3889/oamjms.2018.236

5. Tchernev G. One Step Melanoma Surgery for Patient with Thick Primary Melanomas: „To Break the Rules, You Must First Master Them!“ Open Access Maced J Med Sci. 2018;6(2):367-371. doi: 10.3889/ oamjms.2018.084

6. Tchernev G. Novel Surgical Approach in Cutaneous Melanoma Patients: „Daring Ideas Are Like Chessmen Moved Forward. They May Be Beaten, But they May Start a Winning Game!?“Open Access Maced J Med Sci. 2017;5(6):810-812. doi: 10.3889/oamjms.2017.199

7. Bray F, Ferlay J, Soerjomataram I, Siegel RL, Torre LA, Jemal A. Global cancer statistics 2018: GLOBOCAN estimates of incidence and mortality worldwide for 36 cancers in 185 countries.CA Cancer J Clin. 2018;68(6):394-424. doi: 10.3322/caac.21492

8. Chaput L, Laurent E, Pare A, Sallot A, Mourtada Y, Ossant F et al. Onestep surgical removal of cutaneous melanoma with surgical margins based on preoperative ultrasound measurement of the thickness of the melanoma. Eur J Dermatol. 2018;28(2):202-208. doi: 10.1684/ ejd.2018.3298

9. Thomas C. NEJM editor: "No longer possible to believe much of clinical research published." The Ethical Nag. Marketing Ethics for the Easily Swayed. Nov 9, 2009.

10. Perry S. Ex-editor of NEJM tells how Big Pharma has corrupted academic institutions.MINNPOST/Second opinion. May 5, 2010.

11. Guitera P, Li LX, Crotty K, Fitzgerald P, Mellenbergh R, Pellacani G et al. Melanoma histological Breslow thickness predicted by 75 MHz ultrasonography. Br J Dermatol. 2008;159(2):364-369. doi: 10.1111/j.1365-2133.2008.08681.x

12. Fung J. The Corruption of Evidence Based Medicine-Killing for Profit. Medium HEALTH, April 10, 2018.

13. Thomas K, Ornstein C. Top Sloan Kettering Cancer Doctor Resigns After Failing to Disclose Industry Ties. The NEW YORK TIMES, Sept 13, 2018.

14. Michalopoullos S. Novartis under scrutiny for alleged pharma scandal in Greece. EURACTIV, Jan 5, 2017.

15. Novartis-Gate: 2 Prime Ministers, 8 Ministers involved in Greece's Kickback Scandal. Keep Talking Greece (Greek News), Blog, Wit \& Drama. Feb 5, 2018.

16. Tchernev G, Temelkova I. Valsartan Induced Melanoma?! First Description in Medical Literature! Open Access Maced J Med Sci. 2018;6 (12):2378-2380. doi: 10.3889/oamjms.2018.517

17. Herman A. Another Potential Carcinogen Found in Valsartan. NEJM Journal Watch. September 17, 2018. 


\section{“You Dream Things; You Say, 'Why?' But I See Things Before My Eyes; And I Say 'Why Not?’”}

18. D’Arrigo T. FDA issues statement as valsartan recalls grow. AphA. September 4, 2018.

19. Wendling P. More Drug Makers Tagged as Valsartan Recall Grows. WebMD. August 13, 2018.

20. Howard J. Valsartan recall: 4 things patients should know. CNN. 2018

21. Shoot B. Another Popular Blood Pressure Drug Has Been Recalled by the FDA Over Potential Cancer Risk. FORTUNE. November 1, 2018.

22. Tchernev G, Temelkova I. "Drug induced melanoma: Irbesartan induced cutaneous melanoma!? First description in the World literature!” Open Access Maced J Med Sci. 2019;7(1).

23. Tchernev G, Temelkova I. "Irbesartan induced cutaneous melanoma !? Second case in the Medical Literature!"Open Access Maced J Med Sci. $2019 ; 7(1)$.
24. By Editor Filled in News. Novartis To Pay $\$ 390$ Million to Settle False Claims Charge. Corporate Crime Reporter. Nov 20, 2015.

25. Lynch S. Novartis to pay $\$ 390$ million in U.S. settlement over pharmacy kickbacks. REUTERS. Nov 20, 2015.

26. Ishikane S, Hosoda H, Nojiri T, Tokudome T, Mizutani T, Miura K et al. Angiotensin II promotes pulmonary metastasis of melanoma through the activation of adhesion molecules in vascular endothelial cells. Biochem Pharmacol. 2018;154:136-147. doi: 10.1016/j. bcp.2018.04.012

27. Hakim G. M. Chishti, The Traditional Healer's Handbook. Rochester, Vermont ; Healing Arts Press: 1988.

28. Hakim Mohammed, On Hippocratic Medicine and The Hippocratic Corpus: Traditional Greco-Arabic and Modern Western Medicine: Conflict or Symbiosis? Karachi, Pakistan; Hamdard Academy : 1975. 